\title{
Article \\ Growth and Characterization of Ce-Doped Luag Single Crystal Fibers from Transparent Ceramics by Laser-Heated Pedestal Method
}

\author{
Yun Dai ${ }^{1,2}$, Zhonghan Zhang ${ }^{1}$, Xibin Wang ${ }^{1,2}$, Zhuowei Lu ${ }^{1,2}$, Huamin Kou ${ }^{1,2}$, Liangbi Su ${ }^{1,2}$ and Anhua Wu ${ }^{1,2, *}$ \\ 1 Key Laboratory of Transparent Optical Functional Inorganic Materials, Shanghai Institute of Ceramics, \\ Chinese Academy of Sciences, Shanghai 201899, China; daiyun@student.sic.ac.cn (Y.D.); \\ zhangzhonghan@mail.sic.ac.cn (Z.Z.); wangxibin@student.sic.ac.cn (X.W.); \\ luzhuowei20@mails.ucas.ac.cn (Z.L.); huaminkou@mail.sic.ac.cn (H.K.); suliangbi@mail.sic.ac.cn (L.S.) \\ 2 Center of Materials Science and Optoelectronics Engineering, University of Chinese Academy of Sciences, \\ Beijing 100049, China \\ * Correspondence: wuanhua@mail.sic.ac.cn
}

\section{check for}

updates

Citation: Dai, Y.; Zhang, Z.; Wang, X.; Lu, Z.; Kou, H.; Su, L.; Wu, A. Growth and Characterization of Ce-Doped Luag Single Crystal Fibers from Transparent Ceramics by Laser-Heated Pedestal Method. Crystals 2021, 11, 1149. https://doi.org/10.3390/ cryst11091149

Academic Editors: Zhaojun Liu and Zhixu Jia

Received: 14 July 2021

Accepted: 16 September 2021

Published: 21 September 2021

Publisher's Note: MDPI stays neutral with regard to jurisdictional claims in published maps and institutional affiliations.

Copyright: (c) 2021 by the authors. Licensee MDPI, Basel, Switzerland. This article is an open access article distributed under the terms and conditions of the Creative Commons Attribution (CC BY) license (https:// creativecommons.org/licenses/by/ $4.0 /)$.

\begin{abstract}
Scintillation single crystal fibers (SCFs) have great potential applications in the new generation of high-energy ray and particle detectors due to their morphological advantages. In this work; Ce:LuAG SCFs with a diameter of $1 \mathrm{~mm}$ were grown along the direction of [111] by laserheated pedestal growth (LHPG) method using a transparent ceramic as the source rod; and a doping concentration was $0.1 \mathrm{at} \%, 0.3 \mathrm{at} \%, 1 \mathrm{at} \%$, respectively. The effects of growth rate and annealing in air on the scintillation and optical properties of SCF are discussed in detail. The results of analyzing the absorption spectra; radioluminescence (RL) spectra; pulse-height spectra and fluorescence lifetime of SCFs show that the SCF maintains excellent scintillation performance while having a fiber structure. Therefore; Ce:LuAG SCF is a potential candidate material for detector.
\end{abstract}

Keywords: Ce:LuAG; single crystal fiber; crystal growth; scintillation

\section{Introduction}

At present, inorganic scintillation materials have been widely studied because of their irreplaceable role in the fields of high energy physics, medical imaging and nuclear energy technology, etc. [1-4]. In addition to the traditional inorganic scintillation crystals BGO and $\mathrm{NaI}$ [5], which have been widely used, YAG [6], LuAG [7], YAP [8], and $\mathrm{Lu}_{2} \mathrm{SiO}_{5}$, $\mathrm{Lu}_{2-\mathrm{x}} \mathrm{Y}_{\mathrm{x}} \mathrm{SiO}_{5}$ (LSO, LYSO) $[9,10]$ and $\mathrm{Y}_{2} \mathrm{SiO}_{5}$ (YSO) [11] have also been rapidly developed under the promotion of application requirements. In addition, some new perspective materials such as $\mathrm{Bi}_{2} \mathrm{O}_{3}-\mathrm{Na}_{2} \mathrm{O}-\mathrm{TiO}_{2}-\mathrm{ZnO}-\mathrm{TeO}_{2}$ [12] and $\mathrm{Bi}$ Coatings [13] also show good performance in radiation shielding and detection, but their application in detectors is not very mature. Among them, Ce:LuAG has relatively high density, high effective atomic number $\left(\rho=6.7 \mathrm{~g} / \mathrm{cm}^{3}\right.$, Zeff $\left.=60\right)$, short decay time $(\sim 50 \mathrm{~ns})$, high theoretical light yield (25,000 photons $\left.\mathrm{MeV}^{-1}\right)$ [14-16], and good mechanical and chemical stability. Moreover, the wide emission of $5 \mathrm{~d}-4 \mathrm{f}$ radiative transition of $\mathrm{Ce}^{3+}$ at $530 \mathrm{~nm}$ matches the spectral sensitivity of photodetectors used in high energy physics very well [17], so Ce:LuAG is considered to be one of the representatives of a new generation of scintillator crystals. Table 1 [5] summarizes the properties of commonly used scintillator materials. It can be seen from Table 1 that the light yield of $\mathrm{Ce}^{3+}$ doped LuAG crystal is comparable to that of LYSO crystal. In addition, the short radiation length $(1.41 \mathrm{~cm})$ and the proper interaction length $(23.3 \mathrm{~cm})$ of LuAG crystal can provide a large enough stopping power for the hadron energizer. LuAG crystals are excellent Cherenkov radiators with short absorption edge $(177 \mathrm{~nm})$, large transmission ratio and high refractive index (1.84) [18]. Caltech conducted neutron and proton irradiation experiments on Ce:LuAG, and found that Ce:LuAG has 
the best antiradiation performance among the materials known at present, and the absorption coefficient of neutron and proton irradiation is only half of that of LYSO [19]. These outstanding advantages make LuAG crystals an ideal candidate for future high energy physics, especially for high irradiation backgrounds.

Table 1. Scintillation performance summary of common scintillators [5].

\begin{tabular}{ccccccc}
\hline Crystal & $\begin{array}{c}\text { Ex } \\
(\mathbf{n m})\end{array}$ & $\begin{array}{c}\text { Em } \\
\mathbf{( n m )}\end{array}$ & $\begin{array}{c}\text { Decay Time } \\
\mathbf{( n s )}\end{array}$ & $\begin{array}{c}\text { Light Yield } \\
\mathbf{( p h / M e V )}\end{array}$ & $\begin{array}{c}\text { Normalized } \\
\text { to LYSO }\end{array}$ & $\begin{array}{c}\text { Light Yield in } \\
\text { 1st ns } \\
\text { (Ph/MeV) }\end{array}$ \\
\hline LYSO/LSO & 358 & 402 & 40 & 30,000 & 100 & 740 \\
CsI(TI) & 322 & 540 & 1100 & 60,000 & 200 & 55 \\
NaI(TI) & 346 & 410 & 230 & 36,000 & 120 & 160 \\
Ce:GAGG & 430 & 550 & 53 & 34,400 & 115 & 640 \\
Ce:LuAG & 450 & 520 & 50 & 25,000 & 83 & 240 \\
Ce:YAG & 460 & 520 & 70 & 21,000 & 70 & 130 \\
BaF & X-ray & $220 \& 300$ & $0.5 \& 600$ & 13,000 & 43 & 1200 \\
Ce:YAP & 300 & 370 & 34 & 12,000 & 40 & 390 \\
BGO & 304 & 480 & 300 & 8000 & 27 & 27 \\
Sapphire:Ti & 500 & 750 & 3200 & 7900 & 26 & 2.5 \\
CeF & 265 & 301 & 30 & 2600 & 8.7 & 85 \\
Y:BaF & X-ray & $220 \& 300$ & $0.5 \& 600$ & 2000 & 6.7 & 1200 \\
AFO glass & 335 & 365 & 38 & 450 & 1.5 & 12 \\
PWO & 310 & $420 \& 425$ & $10 \& 30$ & 130 & 0.43 & 6 \\
Yb:YAG & 260 & 350 & 2.5 & 110 & 0.37 & 36 \\
Yb:YAP & 260 & 350 & 1.1 & 57 & 0.19 & 34 \\
\hline
\end{tabular}

The current methods for growing LuAG single crystals mainly include Czochralski (CZ) [20,21], Bridgman (BD) [22,23] and micro-pulling-down ( $\mu$-PD) [24,25]. Among them, the $\mathrm{CZ}$ method and $\mathrm{BD}$ can be used for growing large crystals, but the utilization rate is low and the cost is higher. Although the $\mu$-PD method can grow fibrous LuAG crystals, reducing the production cost of the material, the crucible is needed during the growth process, and the high melting point of LuAG crystals will inevitably bring pollution into the growth process. Another main method for growing inorganic SCFs is the LHPG method. Compared with the above three crystal preparation methods, the biggest advantage of the LHPG method is that it does not need to use a crucible during the growth process. The laser beam directly irradiates the top of the raw material rod to form a melting zone, and then under the traction of the seed crystal, it uses its own surface tension to maintain stability. Its advantages are as follows: (1) it can reduce the impurity pollution caused by the crucible during the growth process; (2) it can grow SCF with a smaller diameter without crucible limitation; (3) its melting zone is small and has a high temperature gradient, so the crystal growth rate is faster. At the same time, preparing the scintillation crystal into a fiber shape can facilitate the construction of a scintillator array detector, which makes up for the limitation of the sensitivity of the electromagnetic probe due to the low effective $Z$ value of the atomic components in the application of plastic/organic scintillator fiber. For example, A. Benaglia [26] developed the Ce:LuAG scintillation array detector and tested the detection performance of high-energy rays with an energy range of $50 \sim 150 \mathrm{GeV}$. M. Nikl [27] also worked on the preparation and research of scintillation SCF.

In this work, we successfully prepared Ce:LuAG SCFs by using the LHPG method, and systematically characterized its scintillation performance. The results show that the Ce:LuAG scintillation crystal still has good scintillation performance after fiberation.

\section{Materials and Methods}

\subsection{Growth of Single Crystal Fibers}

The equipment information about LHPG method has been introduced in literature [28]. The source rod used in the growth process of the LHPG method can be either crystal or 
ceramic. In this work, we used a transparent ceramic as the source rod. The preparation process of transparent ceramics is explained in the literature [29]. The transparent ceramic was cut into a square rod with a section of $1.5 \times 1.5 \mathrm{~mm}^{2}$, and one end of the rod was sharpened with LuAG in $<111>$ direction as the seed crystal. In the high purity nitrogen atmosphere, the ceramic source rod is placed in an appropriate position, so that the $\mathrm{CO}_{2}$ laser can form a stable melting zone on its top, as shown in Figure 1a. The seed crystal is slowly placed in the melting zone and the laser is adjusted to the appropriate power. The appropriate fiber diameter can be obtained by controlling the ratio of the seed lifting speed $V_{f}$ to the source rod feeding speed $V_{S}$. This ratio is generally $1 / 2-1 / 3$ [30]. To maintain the dimension and quality of the SCFs, according to experience, we chose a source rod feeding speed of $8 \mathrm{~mm} / \mathrm{h}$ and $16 \mathrm{~mm} / \mathrm{h}$, respectively to grow $1 \mathrm{~mm}$ diameter SCFs. According to the law of the conservation of mass, we can easily calculate a crystal growth rate of $22.5 \mathrm{~mm} / \mathrm{h}$ and $45 \mathrm{~mm} / \mathrm{h}$, respectively (slightly smaller than the calculated value to compensate for the density difference between the transparent ceramics and the crystal).

Using transparent ceramic as the source rod, we grew Ce:LuAG SCFs with doping concentrations of $0.1 \mathrm{at} \%, 0.3$ at $\%$ and 1 at $\%$, respectively. The length of the fibers could exceed $200 \mathrm{~mm}$. After being cut into $\Phi 1 \times 3 \mathrm{~mm}^{3}$, the fibers were put into muffle furnace to rise to $1400{ }^{\circ} \mathrm{C}$ at $50{ }^{\circ} \mathrm{C} / \mathrm{h}$, and annealed in air for $30 \mathrm{~h}$. The growing SCFs and the transparent ceramic used are shown in Figure 2.

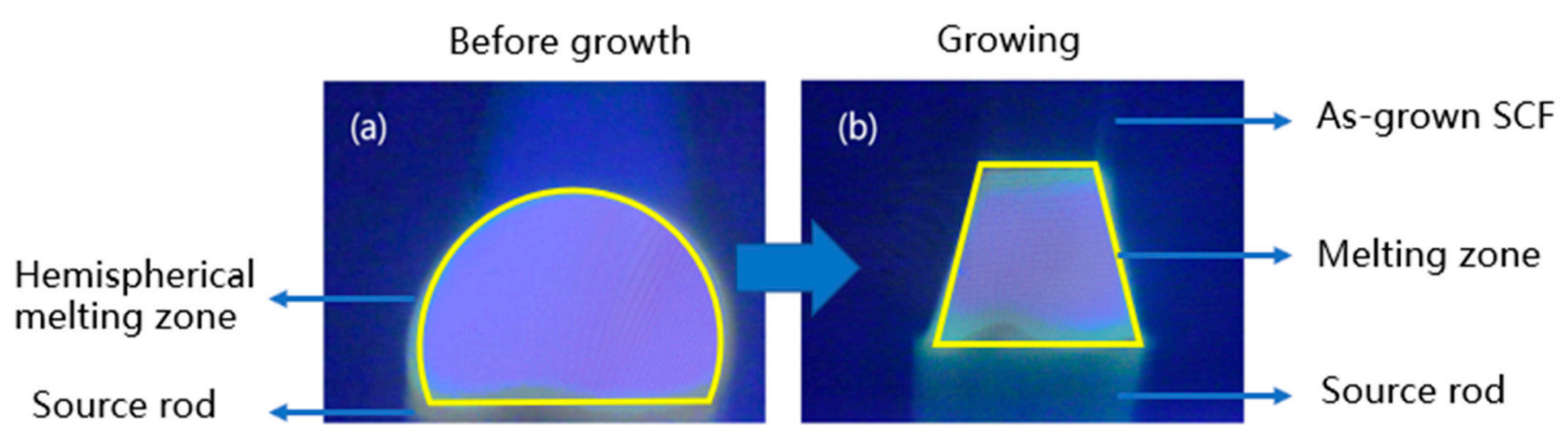

Figure 1. (a) Hemispherical melting zone. (b) Trapezoidal melting zone.

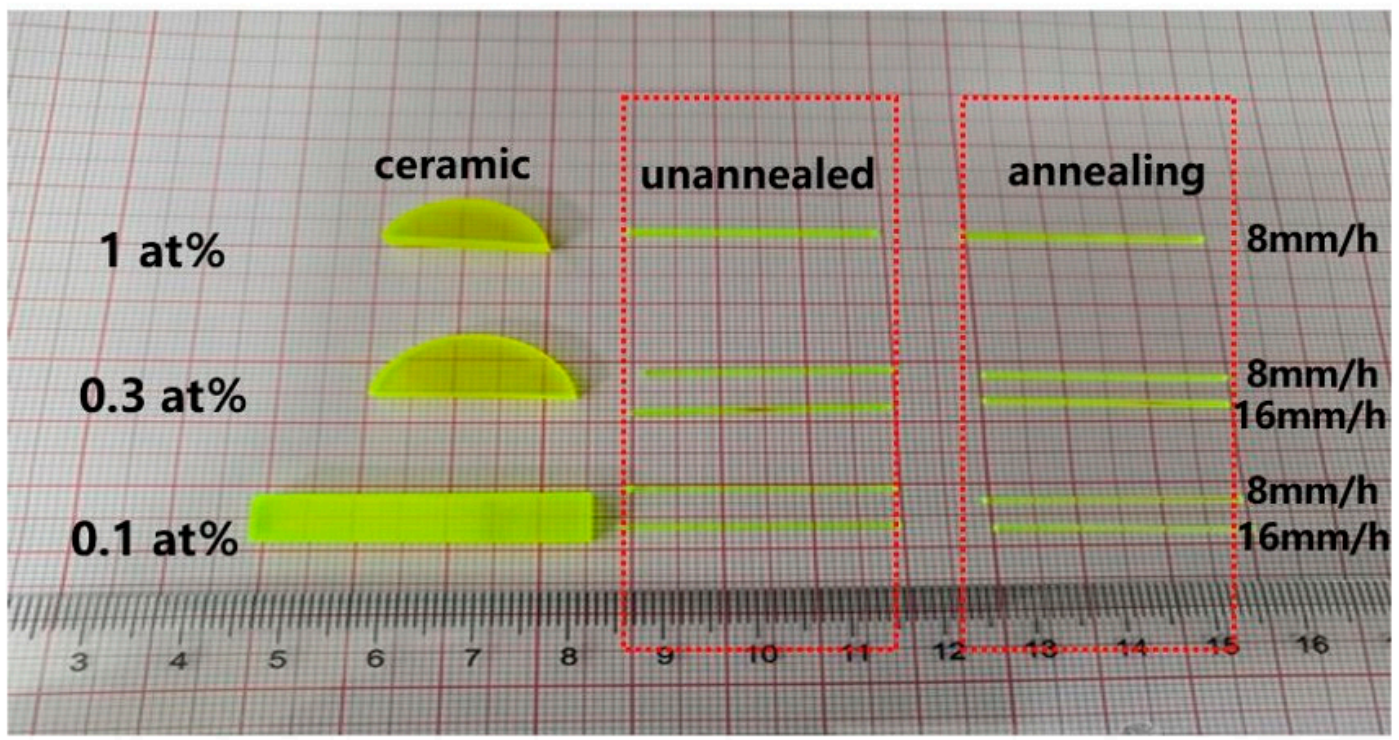

Figure 2. As-grown Ce:LuAG SCFs. 


\subsection{Characterization}

The absorption spectra within the range of 200 800 nm of Ce:LuAG SCFs were collected on a Lambda750 UV/VIS/NIR spectrometer using a resolution setting of $1 \mathrm{~nm}$ at room temperature and the size of samples was $\varnothing=1 \times 2.5 \mathrm{~mm}^{3}$. The radioluminescence (RL) measurements were performed on an X-ray Excited Luminescence (XEL) Spectrometer built by Shanghai Institute of Ceramics, Chinese Academy of Science. An X-ray tube (F30III$2, \mathrm{~V}=50 \mathrm{kV}$ and $\mathrm{I}=500 \mathrm{~mA}$ ) equipped with a tungsten target was applied as the excitation source. The Hamamatsu R928 photomultiplier tube was used as a detector. The pulseheight (energy) spectra were recorded by an ORTEC digiBASE multichannel spectrometer. The sample with the size of $\varnothing=1 \times 4 \mathrm{~mm}^{3}$ was excited by $662 \mathrm{KeV}$ gamma ray from a ${ }^{137} \mathrm{Cs}$ source. The SCF was optically coupled to the light entrance window of the PMT R6233 with an optical grease. The high voltage was supplied by ORTEC 556 high voltage power supply, and signals were read out from the anode of PMT. Then, the signals passed ORTEC 570 shaping amplifier with $10 \mu$ s shaping time, and were converted to digital signals by a Pocket MCA 8000 A multi-channel analyzer (MCA) provided by Amptek Co. Nanosecond flashing light was used as the excitation source. The fluorescence lifetimes were recorded by the spectrofluorometer under $447 \mathrm{~nm}$ excitation (FLS980PL Edinburgh).

\section{Results and Discussion}

\subsection{Spectral Properties}

Figures 3 and 4 reveal the effects of growth rate, Ce ion concentration and annealing on the absorption spectra and X-ray excitation emission spectra of Ce:LuAG SCFs. It can be seen from Figure 3a that Ce:LuAG SCFs still retain the basic properties of crystals. The absorption peaks at $350 \mathrm{~nm}$ and $450 \mathrm{~nm}$ correspond to $4 \mathrm{f}-5 \mathrm{~d}$ transition of $\mathrm{Ce}^{3+}$ ions.

As can be seen from Figure $3 b$, the absorption coefficient of SCF with a slower growth rate is greater than that of SCF with a faster growth rate at the same concentration. In combination with Figure $4 \mathrm{~b}$, it can also be found that SCF with a faster growth rate has a higher luminous intensity. From Figure $4 b$, the luminescence associated with the antisite of Lu-Al can be detected in the UV region [31] and it can be seen that the luminous intensity is higher when the growth rate is faster, so the rapid growth can inhibit the generation of antilocation defects to a certain extent. In turn, it affects the absorption intensity and emission intensity. However, it can be predicted that if the growth rate is too fast, other types of defects will easily occur that will affect SCF luminescence. Combined with Figures $3 \mathrm{c}$ and $4 \mathrm{c}$, it can be seen that with the increase in Ce ion concentration, both its absorption and excitation spectra gradually increase. Combined with Figures $3 \mathrm{~d}$ and $4 \mathrm{~d}$, it can be seen that annealing has little effect on the absorption intensity, but the emission intensity of 1 at $\%$ Ce:LuAG decreases, and that of 0.3 at $\%$ Ce:LuAG increases, while that of 0.1 at $\%$ Ce:LuAG almost remains unchanged. The possible reason is that we use transparent ceramic as the source rod, which contains $\mathrm{Mg}^{2+}$ and other fluxing agents, so some $\mathrm{Ce}^{4+}$ ions will be generated. After annealing in the air, the $\mathrm{Ce}^{3+}$ ions will be reduced and then its luminescence will be weakened, but defects will also be reduced and the luminescence intensity will be increased. As for 1 at $\%$ Ce:LuAG, there are more defects due to the excessive content of Ce ions. After annealing, only some of the defects are eliminated, but the content of $\mathrm{Ce}^{4+}$ will greatly increase, resulting in a decrease in the luminescence intensity. The content of the $\mathrm{Ce}^{4+}$ ion in 0.3 at $\%$ Ce:LuAG increases somewhat after annealing, but the defects are greatly reduced after annealing and the luminescence intensity increases due to its low concentration. The content of $\mathrm{Ce}^{4+}$ ions in 0.1 at $\%$ Ce:LuAG has increased, which weakens the luminescence, but also eliminates some defects and enhances the luminescence. The luminescence intensity is almost constant after they have cancelled each other out. 
(a)

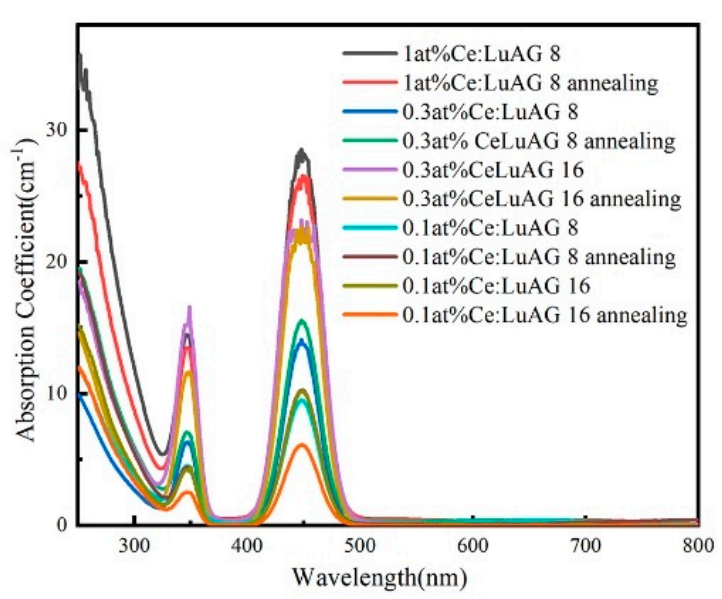

(c)

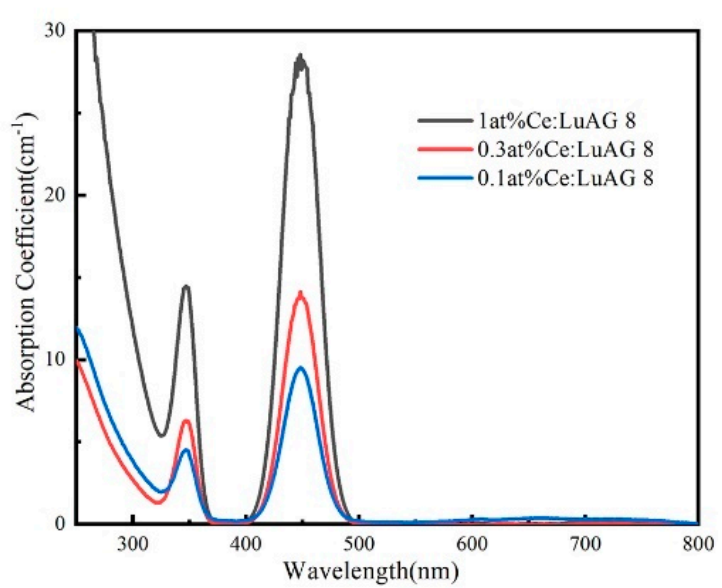

(b)

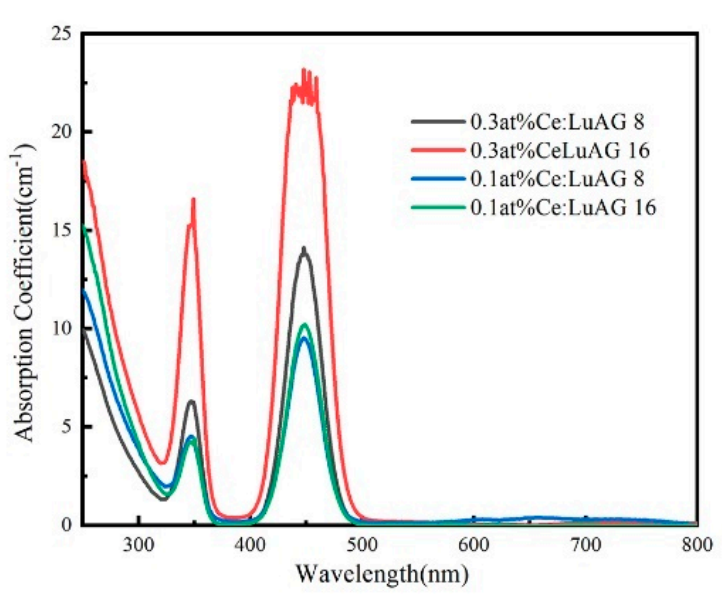

(d)

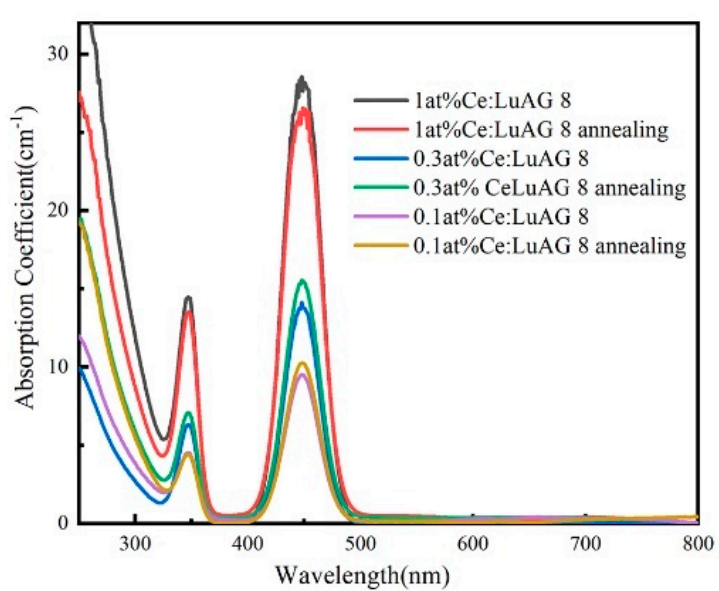

Figure 3. (a) Absorption spectra of all Ce:LuAG SCFs; (b) Absorption spectra at different growth rates; (c) Absorption spectra at different concentrations; (d) Effect of annealing on absorption spectra.

(a)

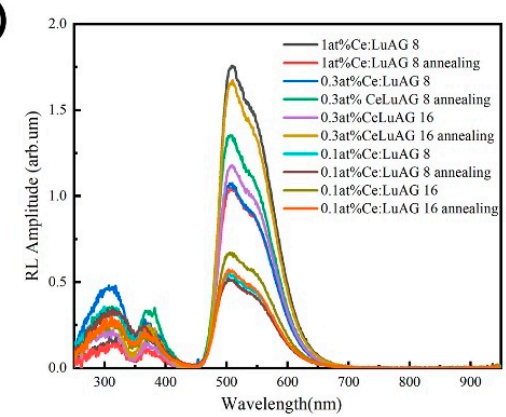

(c)

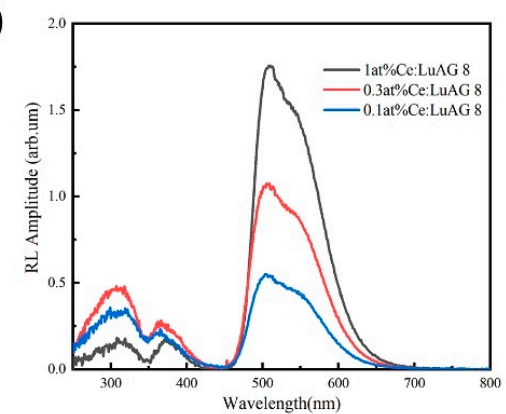

(b)

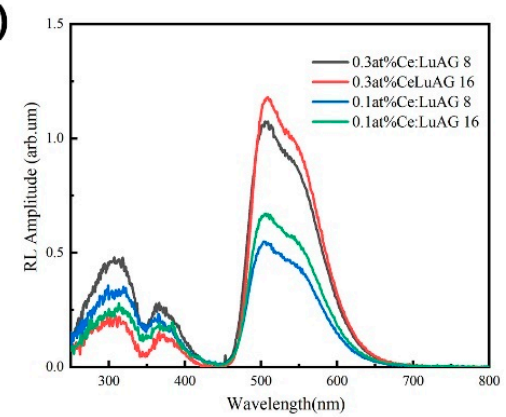

(d)

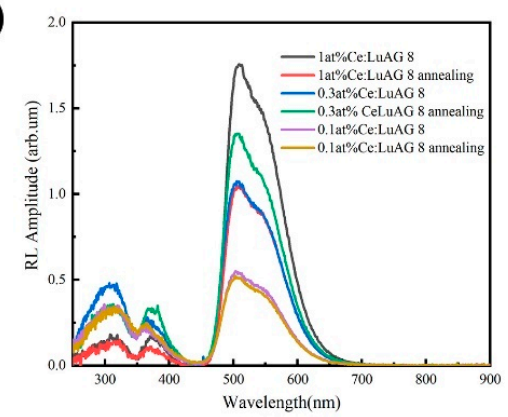

Figure 4. (a) Radioluminescence spectra of all Ce:LuAG SCFs; (b) Radioluminescence spectra at different growth rates; (c) Radioluminescence spectra at different concentrations; (d) Effect of annealing on radioluminescence spectra. 


\subsection{Scintillation Properties of Ce:LuAG SCF}

Figure $5 a$ shows the pulse height spectra of all samples. As can be seen from Figure $5 b$, the number of channels in the pulse height spectra of SCF with fast growth rate at the same concentration is slightly increased. It means that light yield increases, corresponding to the spectral properties mentioned above. It can be seen from Figure $5 c$ that doping with different concentrations has little effect on the track number of pulse height spectra. It can be clearly seen in Figure $5 d$ that the trace number of pulse height spectra increases after annealing at different concentrations. This is because annealing can increase the content of $\mathrm{Ce}^{4+}$ ions and reduce defects such as vacancy and residual stress generated by growth in nitrogen atmosphere. All of these are beneficial to increase its light yield. The energy resolution (ER) was calculated using the full width at half maximum (FWHM) and the MCA channel number value of the peak obtained from the Gauss fit of the full energy peak area. The calculated FWHM, peak and energy resolution are shown in Table 2.

(a)

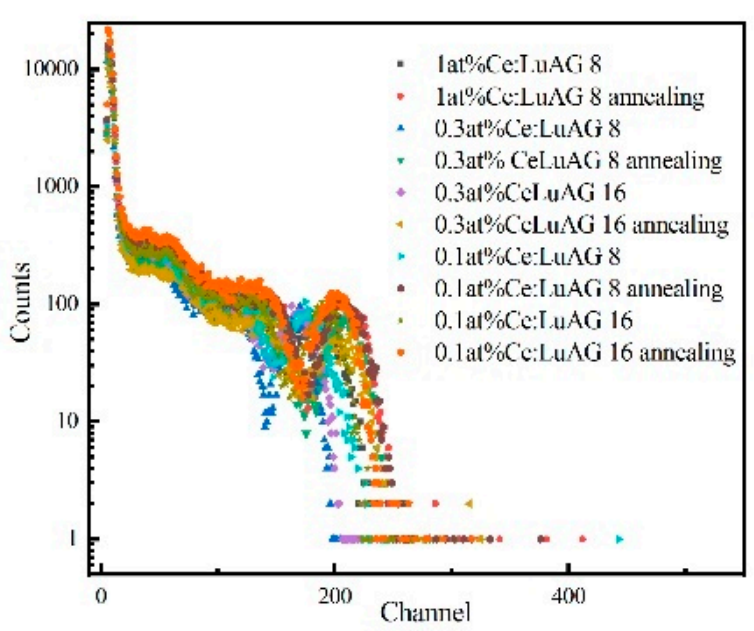

(c)

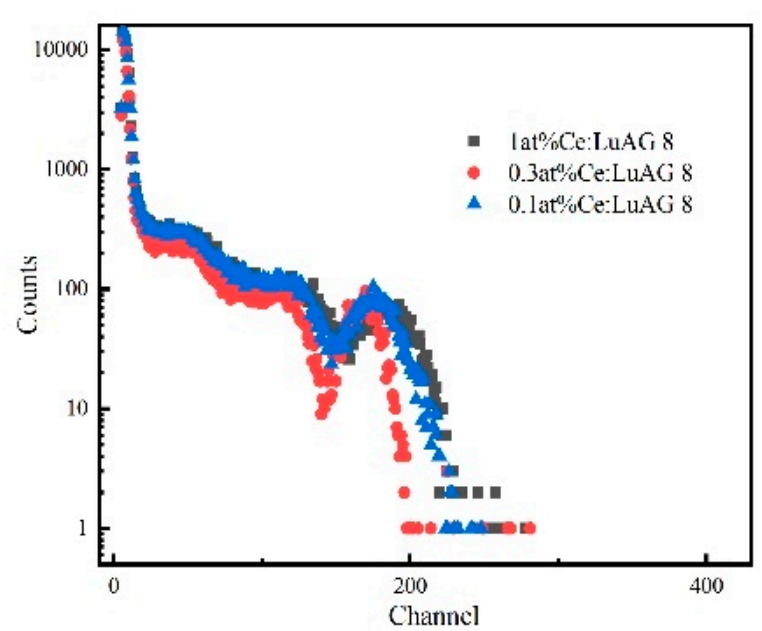

(b)

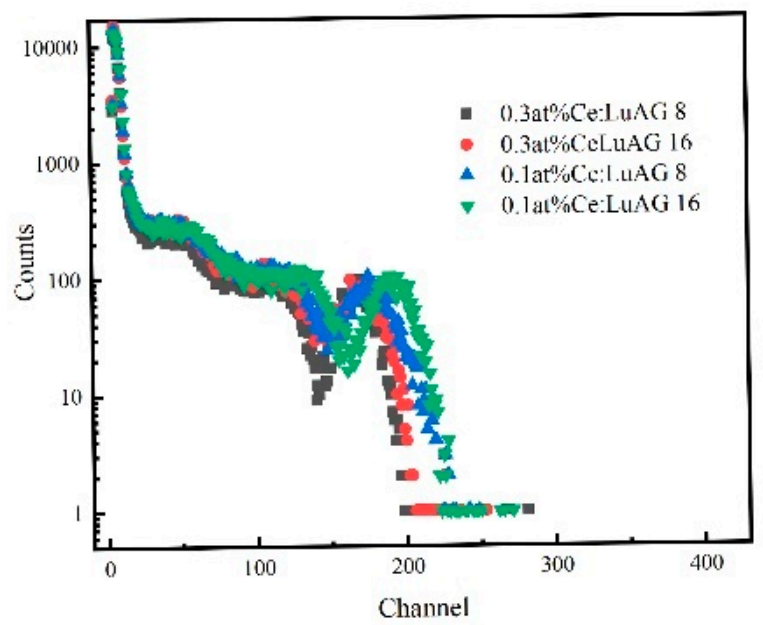

(d)

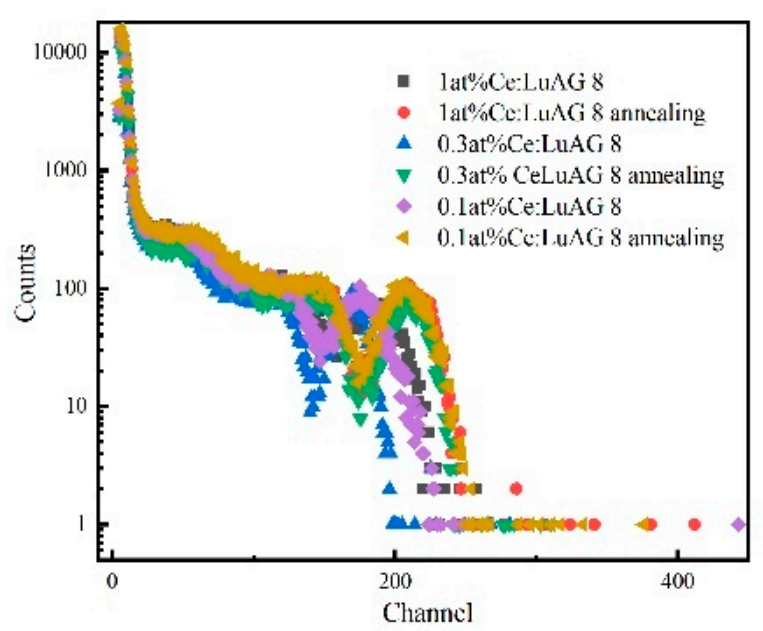

Figure 5. (a) Pulse height spectra of all Ce:LuAG SCFs; (b) Pulse height of spectra at different growth rates; (c) Pulse height spectra at different concentrations; (d) Effect of annealing on R Pulse height spectra.

Figure 6 shows the fluorescence decay curve corresponding to $\mathrm{Ce}^{3+} 5 \mathrm{~d}-4 \mathrm{~F}$ transition in Ce:LuAG SCFs under different conditions. A single exponential equation was used to fit the data, and the fluorescence lifetime was also listed in the Figure 6 and Table 2. It can be seen that it has the same decay curve as transparent ceramics [31]. Is the characteristic decay time of $5 \mathrm{~d}-4 \mathrm{~F}$ transition of $\mathrm{Ce}^{3+}$. Compared with the results of the fluorescence spectrum, it can be seen that when the growth rate is faster, the luminescence intensity is slightly increased, and the corresponding decay time is slightly increased or unchanged, which may be because the rapid growth rate cannot only inhibit the inverse defects, but 
also produce other types of defects that affect the fluorescence attenuation. At the same concentration and the same growth rate, the emission decay time of 1 at $\%$ Ce:LuAG is slightly increased after annealing, while the emission decay time of 0.3 at $\%$ Ce:LuAG and 0.1 at $\%$ Ce:LuAG is slightly decreased, which may be due to the increase in $\mathrm{Ce}^{4+}$ after annealing in air, so the decay time is faster [31]. However, due to the high doping concentration in $1 \mathrm{at} \%$, there are many defects which cannot be completely eliminated by annealing. At the same time, $\mathrm{Ce}^{4+}$ itself does not emit light. After annealing, $\mathrm{Ce}^{3+}$ ions are reduced, but $\mathrm{Ce}^{4+}$ is excessive, so its decay time is slightly increased.
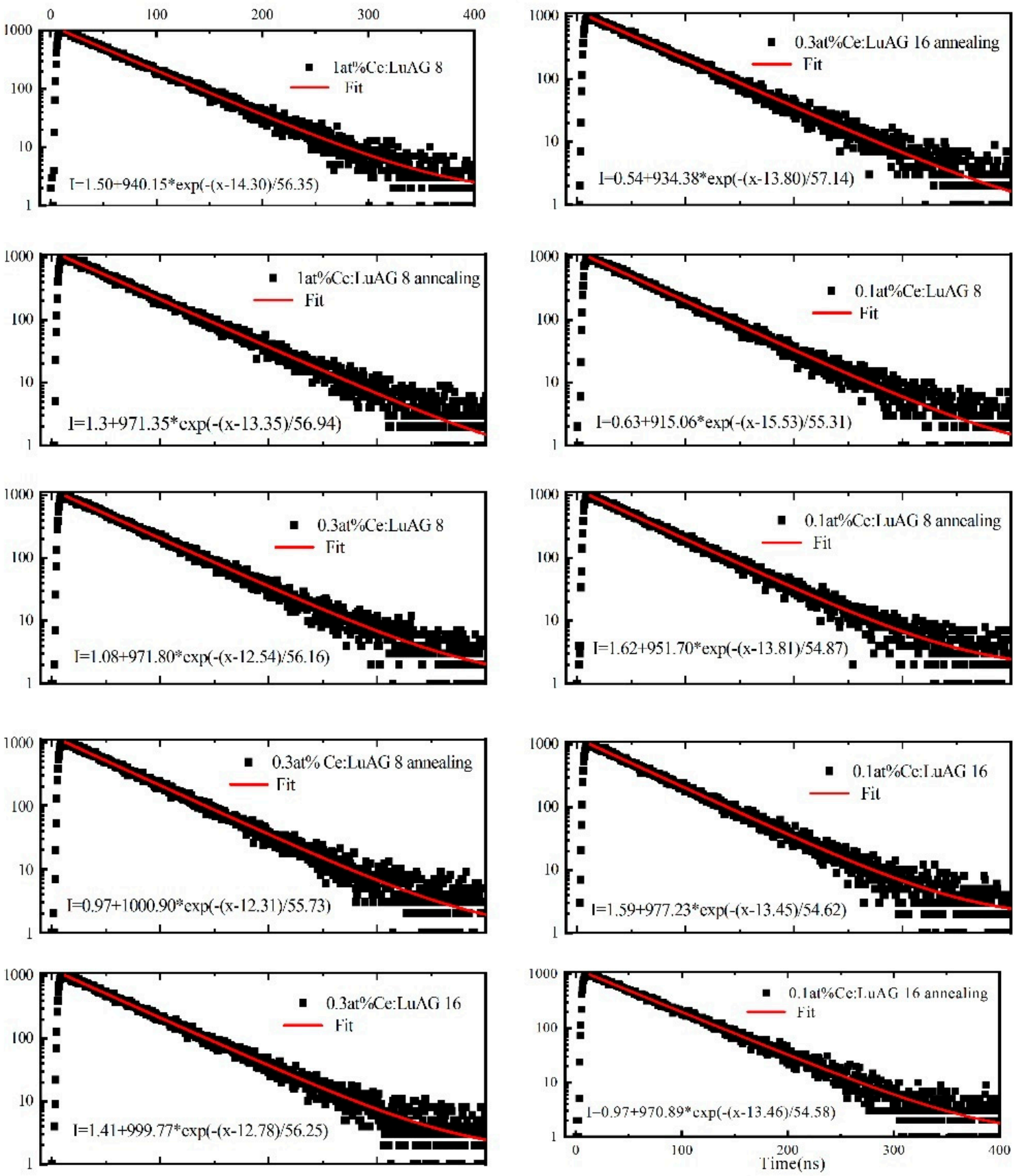

Figure 6. The fluorescence lifetimes of all Ce:LuAG SCFs. 
Table 2. SCFs sample characteristics, energy resolution and fluorescence lifetime with different Ce dopant concentrations.

\begin{tabular}{ccccccc}
\hline SCFs & $\begin{array}{c}\text { Growth Speed } \\
\mathbf{m m} / \mathbf{h}\end{array}$ & Annealing & Peak & FWHM & $\begin{array}{c}\text { Energy Resolution } \\
{[\%]}\end{array}$ & $\begin{array}{c}\text { Fluorescence Lifetime } \\
\text { ns }\end{array}$ \\
\hline 1 at\% Ce:LuAG & 8 & No & 187.64 & 24.75 & 13.19 & 56.35 \\
1 at\% Ce:LuAG & 8 & Yes & 211.7 & 32.67 & 15.43 & 56.95 \\
0.3 at\% Ce:LuAG & 8 & No & 169.32 & 22.82 & 13.48 & 56.16 \\
0.3 at\% Ce:LuAG & 8 & Yes & 209.44 & 29.90 & 14.28 & 55.73 \\
0.3 at\% Ce:LuAG & 16 & No & 169.88 & 19.41 & 11.43 & 56.25 \\
0.3 at\% Ce:LuAG & 16 & Yes & 208.51 & 31.49 & 15.10 & 57.14 \\
0.1 at\% Ce:LuAG & 8 & No & 175.82 & 26.43 & 15.03 & 55.31 \\
0.1 at\% Ce:LuAG & 8 & Yes & 207.18 & 33.33 & 16.08 & 54.87 \\
0.1 at\% Ce:LuAG & 16 & No & 190.67 & 24.51 & 12.85 & 55.31 \\
0.1 at $\%$ Ce:LuAG & 16 & Yes & 200.95 & 30.46 & 15.16 & 54.58 \\
\hline
\end{tabular}

According to the comprehensive properties and spectral properties in Table 2, under low concentration doping, faster growth rate $(16 \mathrm{~mm} / \mathrm{h})$ and annealing can improve the scintillation performance of optical fibers. At the same time, the performance of Ce:LuAG grown by different growth methods was compared in Table 3 [3,31,32]. It can be seen from the table that the SCFs grown by LHPG method still retains the basic properties of single crystal. Moreover, Since there is no crucible restriction during the growth process, this method can also grow SCF with smaller diameter $(\leq 200 \mu \mathrm{m})$ and longer length. Because of its large temperature gradient, it also has a faster growth rate than other methods.

Table 3. Comparison of performance of Ce:LuAG grown by different growth methods.

\begin{tabular}{cccccc}
\hline Method & $\begin{array}{c}\text { Ce Concentration } \\
\mathbf{( \% )}\end{array}$ & $\begin{array}{c}\text { Growth } \\
\text { Speed } \\
\mathbf{m m} / \mathbf{h}\end{array}$ & $\begin{array}{c}\text { Energy } \\
\text { Resolution } \\
{[\%]}\end{array}$ & $\begin{array}{c}\text { Fluorescence } \\
\text { Lifetime } \\
\text { [ns] }\end{array}$ & Ref \\
\hline$\mu-$ PD & 0.1 & 30 & $/$ & $/$ & {$[3]$} \\
CZ & 0.25 & 1 & $/$ & 48 & {$[32]$} \\
transparent & 0.3 & $/$ & 15.6 & 58 & {$[31]$} \\
$\begin{array}{c}\text { ceramics } \\
\text { This work }\end{array}$ & 0.3 & 45 & 11.4 & 56 & $/$ \\
\hline
\end{tabular}

\section{Conclusions}

In this paper, Ce:LuAG SCFs with a diameter of $1 \mathrm{~mm}$ and different Ce ion doping concentrations were successfully grown by the LHPG method using transparent ceramics as the source rod. The effects of different growth rates, concentrations and annealing on SCFs scintillation and optical properties were discussed in detail by analyzing the results of the X-ray excitation spectrum, fluorescence spectrum, lifetime and multichannel energy spectrum. The results show that, due to the characteristics of LHPG method, low concentration doping $(0.3 \mathrm{at} \%, 0.1 \mathrm{at} \%)$, fast growth rate $(45 \mathrm{~mm} / \mathrm{h})$ and the annealing process can improve the scintillation performance of SCFs. The scintillation properties of the grown SCFs are similar to those of single crystal and transparent ceramics. Therefore, the SCF retains the basic properties of bulk single crystal while having a fiber structure. In further work, we will grow SCFs with smaller diameters on the basis of this work and try to build scintillation array detectors with high spatial resolution by the SCF.

Author Contributions: Conceptualization: L.S. and A.W.; Investigation, X.W. and Z.L.; Writingoriginal draft, Y.D.; Writing - review \& editing, Z.Z. and H.K. All authors have read and agreed to the published version of the manuscript. 
Funding: This work was supported by the International Partnership Program of Chinese Academy of Sciences (121631KYSB20180045). This work was also supported by National Natural Science Foundation of China (51872309, U1832106, 61925508, 62005302), Science and Technology Commission of Shanghai Municipality (20511107400, ZJ2020-ZD-005) and Science Foundation for Youth Scholar of State Key Laboratory of High Performance Ceramics and Superfine Microstructures (SKL201904).

Data Availability Statement: The data presented in this study are available on request from the corresponding author.

Acknowledgments: Special thanks to Dongzhou Ding of Shanghai Institute of Ceramics, Chinese Academy of Sciences for the support in measuring the optical fiber scintillation performance.

Conflicts of Interest: The authors declare no conflict of interest.

\section{References}

1. Moszyński, M.; Ludziejewski, T.; Wolski, D.; Klamra, W.; Norlin, L. Properties of the YAG:Ce scintillator. Nucl. Instrum. Methods Phys. Res. Sect. A Accel. Spectrometers Detect. Assoc. Equip. 1994, 345, 461-467. [CrossRef]

2. Van Eijk, C.W.E. Inorganic-scintillator development. Nucl. Instrum. Methods Phys. Res. Sect. A Accel. Spectrometers Detect. Assoc. Equip. 2001, 460, 1-14. [CrossRef]

3. Djebli, A.; Boudjada, F.; Pauwels, K.; Kononets, V.; Patton, G.; Benaglia, A.; Lucchini, M.; Moretti, F.; Sidletskiy, O.; Dujardin, C.; et al. Growth and characterization of Ce-doped YAG and LuAG fibers. Opt. Mater. 2017, 65, 65-68. [CrossRef]

4. Witkiewicz-Lukaszek, S.; Mrozik, A.; Gorbenko, V.; Zorenko, T.; Bilski, P.; Fedorov, A.; Zorenko, Y. LPE Growth of composite thermoluminescent detectors based on the $\mathrm{Lu}_{3-\mathrm{x}} \mathrm{GdxAl}_{5} \mathrm{O}_{12}$ :Ce single crystalline films and YAG:Ce Crystals. Crystals 2020, 10, 189. [CrossRef]

5. Hu, C.; Zhang, L.Y.; Zhu, R.Y.; Demarteau, M.; Wagner, R.; Xia, L.; Xie, J.Q.; Li, X.; Wang, Z.H.; Shih, Y.H.; et al. Ultrafast inorganic scintillator-based front imager for Gigahertz Hard X-ray imaging. Nucl. Instrum. Methods Phys. Res. A 2019, 940, $223-229$. [CrossRef]

6. Kotaki, A.; Yoshino, M.; Yokota, Y.; Hanada, T.; Yamaji, A.; Toyoda, S.; Sato, H.; Ohashi, Y.; Kurosawa, S.; Kamada, K. Yoshikawa, A.Crystal growth and scintillation properties of tube shape-controlled Ce-doped $\mathrm{Y}_{3} \mathrm{Al}_{5} \mathrm{O}_{12}$ single crystals grown by micro-pullingdown method. Appl. Phys. Express 2020, 13, 125503. [CrossRef]

7. Jiuping, Z.; Hongbin, L.; Qiang, S.; Guobin, Z.; Pieter, D.; Danang, B.M. Effects of Annealing Treatments on Luminescence and Scintillation Properties of Ce:Lu $\mathrm{Al}_{5} \mathrm{O}_{12}$ Crystal Grown by Czochralski Method. J. Rare Earths 2007, 25, 568-572. [CrossRef]

8. Alshourbagy, M.; Bigotta, S.; Herbert, D.; Del Guerra, A.; Toncelli, A.; Tonelli, M. Optical and scintillation properties of Ce ${ }^{3+}$ doped $\mathrm{YAlO}_{3}$ crystal fibers grown by mu-pulling down technique. J. Cryst. Growth 2007, 303, 500-505. [CrossRef]

9. Farhi, H.; Lebbou, K.; Belkahla, S.; Grosvalet, L.; Hautefeuille, B.; Caramanian, A.; Dujardin, C.; Tillement, O.; Pedrini, C. Fiber single crystal growth by LHPG technique and optical characterization of $\mathrm{Ce}^{3+}$-doped $\mathrm{Lu}_{2} \mathrm{SiO}_{5}$. Opt. Mater. 2008, 30, $1461-1467$. [CrossRef]

10. Hautefeuille, B.; Lebbou, K.; Dujardin, C.; Fourmigue, J.M.; Grosvalet, L.; Tillement, O.; Pedrini, C. Shaped crystal growth of $\mathrm{Ce}^{3+}$-doped $\mathrm{Lu}_{2(1-x)} \mathrm{Y}_{2 x} \mathrm{SiO}_{5}$ oxyortho silicate for scintillator applications by pulling-down technique. J. Cryst. Growth 2006, 289, 172-177. [CrossRef]

11. Koschan, M.; Yang, K.; Zhuravleva, M.; Melcher, C. A comparison of the effect of $\mathrm{Ca}^{2+}$ codoping in cerium doped GSO with that of LSO and YSO. J. Cryst. Growth 2012, 352, 133-136. [CrossRef]

12. Sayyed, M.I.; Askin, A.; Zaid, M.H.M.; Olukotun, S.F.; Khandaker, M.U.; Tishkevich, D.I.; Bradley, D.A. Radiation shielding and mechanical properties of $\mathrm{Bi}_{2} \mathrm{O}_{3}-\mathrm{Na}_{2} \mathrm{O}-\mathrm{TiO}_{2}-\mathrm{ZnO}-\mathrm{TeO}_{2}$ glass system. Radiat. Phys. Chem. 2021, 186, 109556. [CrossRef]

13. Tishkevich, D.I.; Grabchikov, S.S.; Lastovskii, S.B.; Trukhanov, S.V.; Zubar, T.I.; Vasin, D.; Trukhanov, A.V.; Kozlovskiy, A.; Zdorovets, M.M. Effect of the Synthesis Conditions and Microstructure for Highly Effective Electron Shields Production Based on Bi Coatings. ACS Appl. Energy Mater. 2018, 1, 1695-1702. [CrossRef]

14. Derdzyan, M.V.; Ovanesyan, K.L.; Petrosyan, A.G.; Belsky, A.; Dujardin, C.; Pedrini, C.; Auffray, E.; Lecoq, P.; Lucchini, M.; Pauwels, K. Radiation hardness of LuAG:Ce and LuAG: Pr scintillator crystals. J. Cryst. Growth 2012, 361, 212-216. [CrossRef]

15. Dujardin, C.; Mancini, C.; Amans, D.; Ledoux, G.; Abler, D.; Auffray, E.; Lecoq, P.; Perrodin, D.; Petrosyan, A.; Ovanesyan, K.L. LuAG:Ce fibers for high energy calorimetry. J. Appl. Phys. 2010, 108, 013510. [CrossRef]

16. Petrosyan, A.G.; Ovanesyan, K.L.; Sargsyan, R.V.; Shirinyan, G.O.; Abler, D.; Auffray, E.; Lecoq, P.; Dujardin, C.; Pedrini, C. Bridgman growth and site occupation in LuAG:Ce scintillator crystals. J. Cryst. Growth 2010, 312, 3136-3142. [CrossRef]

17. Di, J.Q.; Xu, X.D.; Xia, C.T.; Li, D.Z.; Zhou, D.H.; Wu, F.; Xu, J. Crystal growth and optical properties of LuYAG:Ce single crystal. J. Cryst. Growth 2012, 351, 165-168. [CrossRef]

18. Auffray, D.; Abler, S.; Brunner, S.; Frisch, B.; Knapitsch, A.; Lecoq, P.; Mavromanolakis, G.; Poppe, O.; Petrosyan, A. LuAG Material for Dual Readout Calorimetry at Future High Energy Physics Accelerators. In Proceedings of the 2009 IEEE Nuclear Science Symposium Conference Record (NSS/MIC), Orlando, FL, USA, 24 October-1 November 2009; pp. $2245-2249$.

19. Hu, C.; Li, J.; Yang, F.; Jiang, B.; Zhang, L.; Zhu, R.-Y. LuAG ceramic scintillators for future HEP experiments. Nucl. Instrum. Methods Phys. Res. Sect. A Accel. Spectrometers Detect. Assoc. Equip. 2020, 954, 161723. [CrossRef] 
20. Kamada, K.; Yanagida, T.; Pejchal, J.; Nikl, M.; Endo, T.; Tsutsumi, K.; Usuki, Y.; Fujimoto, Y.; Fukabori, A.; Yoshikawa, A. Scintillation properties of Ce doped $\mathrm{Gd}_{2} \mathrm{Lu}(\mathrm{Ga}, \mathrm{Al})_{5} \mathrm{O}_{12}$ single crystal grown by the micro-pulling-down method. J. Cryst. Growth 2012, 352, 35-38. [CrossRef]

21. Sugiyama, M.; Fujimoto, Y.; Yanagida, T.; Yamaji, A.; Yokota, Y.; Yoshikawa, A. Growth and scintillation properties of Nd-doped $\mathrm{Lu}_{3} \mathrm{Al}_{5} \mathrm{O}_{12}$ single crystals by Czochralski and micro-pulling-down methods. J. Cryst. Growth 2013, 362, 178-181. [CrossRef]

22. Tian, T.; Feng, H.; Zhang, Y.; Zhou, D.; Shen, H.; Wang, H.; Xu, J. Crystal Growth and Luminescence Properties of Dy ${ }^{3+}$ and Ge ${ }^{4+}$ Co-Doped $\mathrm{Bi}_{4} \mathrm{Si}_{3} \mathrm{O}_{12}$ Single Crystals for High Power Warm White LED. Crystals 2017, 7, 249. [CrossRef]

23. Petrosyan, A.; Popova, V.; Gusarov, V.; Shirinyan, G.; Pedrini, C.; Lecoq, P. The $\mathrm{Lu}_{2} \mathrm{O}_{3}-\mathrm{Al}_{2} \mathrm{O}_{3}$ system: Relationships for equilibrium-phase and supercooled states. J. Cryst. Growth 2006, 293, 74-77. [CrossRef]

24. Chani, V.; Lebbou, K.; Hautefeuille, B.; Tillement, O.; Fourmigue, J.-M. Evaporation induced diameter control in fiber crystal growth by micro-pulling-down technique: $\mathrm{Bi}_{4} \mathrm{Ge}_{3} \mathrm{O}_{12}$. Cryst. Res. Technol. 2006, 41, 972-978. [CrossRef]

25. Wang, A.; Zhang, J.; Jia, Z.; Ye, S.; Ma, X.; Wu, B.; Wang, S.; Wang, F.; Wang, T.; Zhang, B. Optimized growth and laser application of yb:Luag single-crystal fibers by micro-pulling-down technique. Crystals 2021, 11, 78. [CrossRef]

26. Benaglia, A.; Lucchini, M.T.; Pauwels, K.; Tully, C.; Medvedeva, T.; Heering, A.; Dujardin, C.; Kononets, V.; Lebbou, K.; Aubry, N.; et al. Test beam results of a high granularity LuAG fibre calorimeter prototype. J. Instrum. 2016, 11, P05004. [CrossRef]

27. Nikl, M.; Yoshikawa, A. Recent R\&D Trends in Inorganic Single-Crystal Scintillator Materials for Radiation Detection. Adv. Opt. Mater. 2015, 3, 463-481. [CrossRef]

28. Dai, Y.; Zhang, Z.; Wang, Y.; Su, L.; Li, J.; Lo, C.; Wu, A. Growth of Tm: $\mathrm{Lu}_{3} \mathrm{Al}_{5} \mathrm{O}_{12}$ single crystal fiber from transparent ceramics by laser-heated pedestal method and its spectral properties. Opt. Mater. 2020, 111, 110674. [CrossRef]

29. Liu, S.; Feng, X.; Hu, C.; Kou, H.; Li, J.; Mares, J.A.; Babin, V.; Nikl, M.; D’Ambrosio, C.; Pan, Y. Effect of Li+ ions co-doping on luminescence, scintillation properties and defects characteristics of LuAG:Ce ceramics. Opt. Mater. 2017, 64, 245-249. [CrossRef]

30. Wang, T.; Zhang, J.; Zhang, N.; Wang, S.; Wu, B.; Jia, Z.; Tao, X. The characteristics of high-quality Yb:YAG single crystal fibers grown by a LHPG method and the effects of their discoloration. RSC Adv. 2019, 9, 22567-22575. [CrossRef]

31. Liu, S.P.; Mares, J.A.; Feng, X.Q.; Vedda, A.; Fasoli, M.; Shi, Y.; Kou, H.M.; Beitlerova, A.; Wu, L.X.; D’Ambrosio, C.; et al. Towards Bright and Fast $\mathrm{Lu}_{3} \mathrm{Al}_{5} \mathrm{O}_{12}: \mathrm{Ce}, \mathrm{Mg}$ Optical Ceramics Scintillators. Adv. Opt. Mater. 2016, 4, 731-739. [CrossRef]

32. Yanagida, T.; Fujimoto, Y.; Yokota, Y.; Kamada, K.; Yanagida, S.; Yoshikawa, A.; Yagi, H.; Yanagitani, T. Comparative study of transparent ceramic and single crystal Ce doped LuAG scintillators. Radiat. Meas. 2011, 46, 1503-1505. [CrossRef] 